\title{
Association of follicle-stimulating hormone receptor gene ser680 asn (rs6166) polymorphism with polycystic ovarian syndrome
}

\section{Thathapudi Sujatha $^{1}$, Erukkambattu Jayashankar ${ }^{2}$, Uma Addepally $^{3}$, Kodati Vijayalakshmi ${ }^{1}$, Qurratulain Annie Hasan ${ }^{4}$}

\begin{abstract}
${ }^{1}$ Department of Genetics and Molecular Medicine, Vasavi Medical and Research Centre, Khairatabad, Hyderabad, India

${ }^{2}$ Department of Pathology, Kamineni acdemy of medical sciences and research center, LB Nagar, Hyderabad, India ${ }^{3}$ Department of Biotechnology, Jawaharlal Nehru University of technology, Kukatpally, Hyderabad, India

${ }^{4}$ Kamineni Academy of Medical Sciences and Research Centre, Vasavi Medical and Research Centre, Hyderabad, India
\end{abstract}

Received: 19 January 2016

Accepted: 29 February 2016

\section{*Correspondence:}

Dr. Sujatha Thathapudi,

E-mail: sthathapudi@ymail.com

Copyright: (c) the author(s), publisher and licensee Medip Academy. This is an open-access article distributed under the terms of the Creative Commons Attribution Non-Commercial License, which permits unrestricted non-commercial use, distribution, and reproduction in any medium, provided the original work is properly cited.

\begin{abstract}
Background: Polycystic Ovarian Syndrome (PCOS) is the most common cause of female anovulatory infertility, with a prevalence of 6-10\% among women of reproductive age, characterized by clinical and / or biochemical androgen excess, ovulatory dysfunction and polycystic ovaries. Sex hormones and hormone receptors play a fundamental role in folliculogenesis. Aim of the study was to study the association of follicle-stimulating hormone receptor (FSHR) Ser680Asn; rs6166 gene polymorphism with PCOS in our study population.

Methods: Genetic case-control study, involving 204 women with PCOS and 204 healthy, sex and age matched controls. Anthropometric and biochemical profile were taken in a well-designed proforma. Isolation of deoxyribonucleic acid (DNA) by salting out method and genotype analysis was done for all the study population using Polymerase chain reaction - Restriction fragment length polymorphism (PCR-RFLP).

Results: We have demonstrated an association between FSHR gene, Ser680SAsn (rs6166) polymorphism and PCOS. Frequency of A allele was 0.61 in PCOS and 0.44 in controls (OR 1.98, CI 1.5-2.6, and P value <0.0001) indicates that the A allele is associated with PCOS in our study population. The AA genotype conferred a significant risk of developing PCOS (OR 2.069, CI 1.33-3.211 and P value 0.0012). We found significant elevation of body mass index, LH, LH/FSH with AA genotype of PCOS when compared with controls. The GG genotype showed increased basal FSH levels, insulin resistance in PCOS compared to other genotypes.

Conclusions: FSHR Ser680Asn (rs6166) gene polymorphism is associated with PCOS, and can be used as a relevant molecular biomarker to identify risk of PCOS in our population.
\end{abstract}

Keywords: Polycystic ovarian syndrome, Gene polymorphism, Follicle-stimulating hormone receptor, rs6166 polymorphism

\section{INTRODUCTION}

Polycystic Ovarian Syndrome (PCOS) is the most common cause of female anovulatory infertility, with a prevalence of $6-10 \%$ among women of reproductive age, characterized by clinical and/or biochemical androgen excess, ovulatory dysfunction and polycystic ovaries. ${ }^{1}$ Follicle-stimulating hormone (FSH) is an important hormone for women and a plays a role in the follicle development, oocyte maturation and steroidogenesis 
regulation. ${ }^{2}$ It mediates FSH receptor (FSHR) through its biological functions. FSHR belongs to the G-protein coupled receptor family and consist of 10 exons, 9 introns and the promoter region at chromosome 2p21 the level of FSH is controlled by FSHR, and aberrant FSHR affects ovary and folliculogenesis.

The first nine exons encode for extracellular domain of the receptor, whereas exon 10 encodes for the C-terminal end of extracellular domain, transmembrane domain and intracellular domain of the FSHR. ${ }^{3}$ The C-terminal intracellular domain is rich in Ser/Thr residues, can be phosphorylated by specific intracellular kinases and mediate the transduction of signal originated from FSH/FSHR binding. ${ }^{4}$ Mutations in the FSHR gene are rare, while sequencing showed that FSHR gene contains over 1800 single-nucleotide polymorphisms (SNPs), only a small number of SNPs of the FSHR are located in the protein coding regions (exons) (http://www.ncbi.nlm.nih.gov/SNP). The rs6166 (Ser680Asn) SNP located in the intracellular C-terminal domain has been most extensively studied with respect to frequency and ethnic distribution. The rs6166 is located at nucleotide position 2039 in which $\mathrm{G}$ is replaced by $\mathrm{A}$, which leads to an amino acid change at position 680 from serine (AGT) to aspargine (AAT). ${ }^{5}$ The purpose of this study was to estimate the prevalence of polymorphism of FSH receptor gene at position 680 (rs6166), and to demonstrate the possible association of FSHR Ser680Asn (rs6166) polymorphism with PCOS in our study population.

\section{METHODS}

This study was approved by the institutional ethical committee and informed written consent was obtained from all subjects. In this prospective case-control study we included 204 PCOS patients from Anu"s fertility center, Somajiguda, Hyderabad from July, 2011, to January, 2013.

\section{Inclusion criteria}

Subjects were ranged in age from 17 to 35 years and were diagnosed using the 2006-Androgen Excess Society (AES) criteria: (1). hyperandrogenism, clinical or biochemical and either; (2). Oligo-anovulation or (3). polycystic ovarian morphology.

\section{Exclusion criteria}

Women excluded from the study were those with inherited disorders like congenital adrenal hyperplasia, androgen secreting neoplasms, androgenic/anabolic drug use or abuse, Cushing's syndrome, syndromes of severe insulin resistance, thyroid dysfunction and hyperprolactinemia.

We have recruited 204 controls from a tertiary care hospital, Kamineni Academy of Medical Sciences and
Research Center, LB Nagar, Hyderabad to this study over the same period. Subjects ranged from 17-35 yrs and did not show hirsutism, acne or male-type alopecia. All of them had regular menstrual cycles and none of them satisfied any of the AES-2006 criteria. All the control subjects also underwent an ultrasonographic examination, and women who had any pathologic findings like polycystic ovaries were excluded from the study.

\section{Definitions}

Clinical hyperandrogenism; modified Ferriman-Gallwey (mFG) score $>6$ with or without acne and/or androgenic alopecia. ${ }^{8}$ Hirsutism was scored by studying terminal hair in nine body areas (upper lip, chin, chest, upper and lower abdomen, upper arms, thighs, and upper and lower back). The occurrence of acne was recorded by areas of distribution and degree of affection with lesions (papules, cysts, scars, or abscesses) categorized simply as mild, moderate and severe. Acanthosis nigricans (AN); dark, velvety, skin thickening on the neck, axilla, and other sites such as face, chest and knuckles were recorded. Oligomenorrhoea; absence of menstruation for more than 35 days, amenorrhea; no menstruation for more than 6 months.

The definition of polycystic ovarian morphology by ultrasound examination is the presence of $>12$ follicles with 2 to $9 \mathrm{~mm}$ diameter in the ovary. An ovarian volume of $>10 \mathrm{ml}$ is also suggestive. Only one ovary consistent with PCO morphology is sufficient for diagnosis. ${ }^{9}$ All subjects underwent a transvaginal ultrasound or transabdominal ultrasound in the follicular phase to evaluate ovarian morphology and any lesions in the pelvic area.

Clinical findings: Clinical history included a questionnaire-based interview regarding sociodemographic factors, detailed menstrual and obstetric history, onset and degree of clinical symptoms of PCOS, dietary habits, drug history, family history of PCOD, diabetes, hypertension, and cardiovascular risk factors. Physical examination for body mass index (BMI), waist to hip ratio (WHR), blood pressure, acne, hirsutism, alopecia, male pattern of hair loss, acanthosis nigricans were done.

\section{Sampling}

Two millilitres of peripheral blood was collected in EDTA for DNA isolation and $5 \mathrm{ml}$ of blood in plain vial for serum preparation from all the patients and controls along with clinical data, personal history and family history.

\section{Biochemical and hormonal findings}

Serum preparation was done immediately using centrifuge, and stored in $-20^{\circ} \mathrm{C}$ until processing of biochemical parameters. Fasting plasma glucose 
(enzymatic colorimetric method), serum FSH (Hitachi analyser), LH, insulin, serum testosterone (free and total), androstenedione, and dehydroxy-epiandrostenedione were measured by Enzyme linked immuno sorbent assay (ELISA) in both patients and controls. The cut-off values for male hormones to be considered as abnormal are as follows; Free testosterone $>7.01 \mathrm{ng} / \mathrm{mL}$, Total testosterone $>1 \mathrm{ng} / \mathrm{mL}$, Androstenedione $>2.4 \mathrm{ng} / \mathrm{mL}$, and DHEA >12 ng/mL. Serum cholesterol, triglycerides, HDL was measured using the enzymatic colorimetric assay. Laboratory controls were used to check the accuracy and precision of the analyser, reagents and assay results.

\section{Isolation of DNA and genotype analysis}

Genomic DNA was isolated from the peripheral blood of subjects using salting out method in our laboratory..$^{10,11}$ The DNA was stored at $-20^{\circ} \mathrm{C}$ until processing. Genotyping for the FSHR Ser680Asn gene polymorphism (rs6166) was performed by polymerase chain reaction (PCR), amplification of the fragment of exon 10 was performed with the use of specific oligonucleotide primers, as described elsewhere. ${ }^{12}$ Forward primer: 5'-TTTGTGGTCATCTGTGGCTGC3'; reverse primer: 5' CAAAGGCAAGGACTGAATTATCATT -3' synthesized from Sigma - Aldrich Chemical Pvt Limited (Bangalore, India), followed by restriction fragment length polymorphism (RFLP) analysis. A three-step PCR was performed using XP thermal cycler as described by us earlier. ${ }^{13}$ The PCR reaction was performed in a final volume of $25 \mu \mathrm{L}$ containing 1 x PCR buffer, $2 \mathrm{mM}$ $\mathrm{MgCl} 2,200 \mu \mathrm{M}$ of each dNTP, $10 \mathrm{pM}$ of each primer, 0.2 units of Taq-DNA polymerase (Fermentas, Lithuania) and $25 \mathrm{ng}$ of the DNA template. Briefly the PCR conditions for Ser680Asn variant were as follows: an initial denaturation at $94^{\circ} \mathrm{C}$ for 5 minutes, followed by 30 cycles of denaturation at $94^{\circ} \mathrm{C}$ for 30 seconds, annealing at $55^{\circ} \mathrm{C}$ for 30 seconds and extension at $72^{\circ} \mathrm{C}$ for 1 minute, final extention at $72^{\circ} \mathrm{C}$ for 10 minutes. The 520 bp amplified PCR product was digested with BsrI enzyme (Fermentas, Hannover, MD) for Ser680Asn variant. Digestion was performed in $15 \mu \mathrm{L}$ reaction volume containing $1 \mathrm{x}$ reaction buffer, 0.5 units of restriction enzyme and $10 \mu \mathrm{L}$ of purified PCR product, incubated at $60^{\circ} \mathrm{C}$ for 2 hours. After incubation, products were run on $12 \%$ Poly Acrylamide Gel Electrophoresis (PAGE), at 200 volts for 2 hours. Bands visualized and photographed. Bands of $520 \mathrm{bp}$ in case of AA genotype, 520/413/107 bp in AG genotype, and 413/107 bp in GG genotype were observed.

\section{Data and statistics}

Body mass index $=$ weight $/$ height $^{2}\left(\mathrm{~kg} / \mathrm{m}^{2}\right)$ and Insulin resistance (Homeostatic Model Assessment score) was calculated by using the formula: fasting serum insulin $(\mathrm{uU} / \mathrm{ml}) \mathrm{x}$ fasting plasma glucose $(\mathrm{mg} / \mathrm{dl}) / 405 .^{14}$
Statistical analysis was performed using "Medcalc" statistical software (MSS), USA. Chi squre test $\left(\mathrm{X}^{2}\right)$, odds ratio (OR), and $95 \%$ confidence interval (CI) were done to assess the association between the groups. One-way ANOVA with Bonferroni post hoc test was performed using "Graphpad Insta3" software. A p-value of $<0.05$ was considered statistically significant.

\section{RESULTS}

The age range was 17 to 35 years for both patients and controls. The clinical features of hyperandrogenism, including hirsutism, acne, alopecia etc., irregular menstruation, and polycystic ovaries were shown in Figure 1. Comparison of mean values of anthropometric and biochemical features of PCOS cases and controls were shown in Table 1.

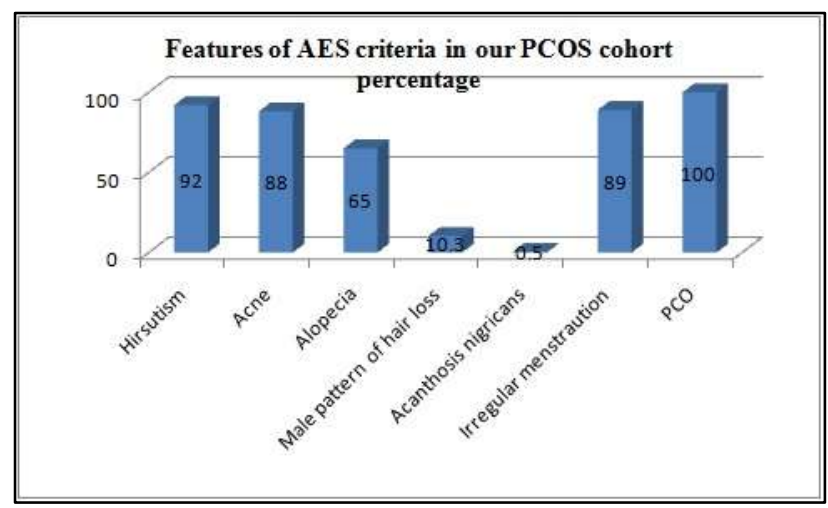

AES: Androgen Excess Society, PCOS- Polycystic Ovary syndrome, PCO-Polycystic ovary.

Figure 1: Features of AES criteria in our PCOS cohort.

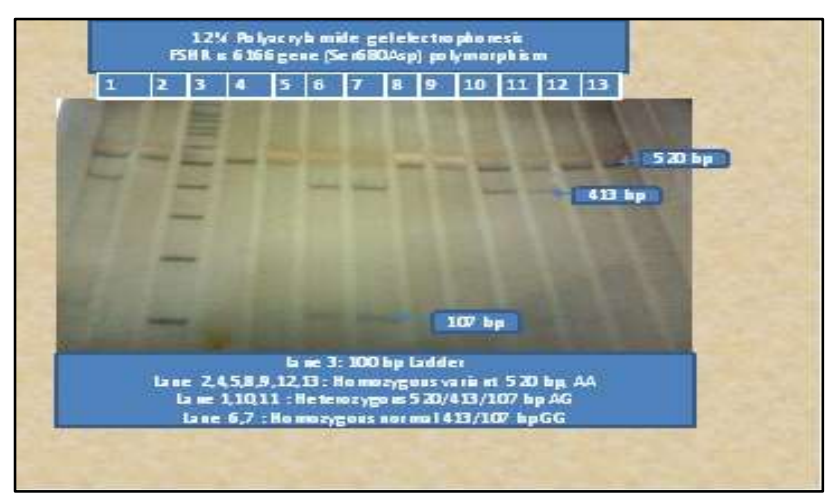

Figure 2: $12 \%$ PAGE - FSHR rs6166 (Ser680ASn) gene polymorphism.

A PCR product of 520 bp was obtained, which on digestion with restriction enzyme Bsr I gave three different patterns for $2039 \mathrm{G} \rightarrow$ A substitution (Ser680Asn variant): fragment $520 \mathrm{bp}$ band indicates AA genotype (for 680Asn/Asn); 520/413/107 bp bands indicates AG genotype (for 680Asn/Ser); and $413 / 107$ bp bands indicates GG genotype (for 680Ser/Ser) (Figure 2). 
Table 1: Comparison of mean values of anthropometric and biochemical characteristics in PCOS patients and controls with their mean and standard deviations.

\begin{tabular}{|llll|}
\hline Parameter & PCOS $(n=204)$ & Controls $(n=204)$ & P value \\
\hline Age $($ years $)$ & $28 \pm 3.6$ & $28 \pm 5.1$ & 1.0000 \\
\hline BMI $\left(\mathrm{Kg} / \mathrm{m}^{2}\right)$ & $27.12 \pm 4.93$ & $23.4 \pm 3.2$ & $<0.0001$ \\
\hline Fasting Glucose $\mathrm{mg} / \mathrm{dl}$ & $88 \pm 8.6$ & $86.85 \pm 7.1$ & 0.0678 \\
\hline Fasting insulin $\mu \mathrm{IU} / \mathrm{ml}$ & $16.94 \pm 7.26$ & $6.66 \pm 3.19$ & $<0.0001$ \\
\hline HOMA score & $3.73 \pm 3.8$ & $1.44 \pm 0.75$ & $<0.0001$ \\
\hline LH IU/l & $11.97 \pm 6.08$ & $7.9 \pm 5.46$ & $<0.0001$ \\
\hline FSH IU/l & $5.48 \pm 1.98$ & $6.47 \pm 3.16$ & 0.0002 \\
\hline LH/FSH & $2.62 \pm 1.2$ & $1.5 \pm 1.2$ & $<0.0001$ \\
\hline Cholesterol $\mathrm{mg} / \mathrm{dl}$ & $161.5 \pm 30.1$ & $162.7 \pm 49$ & 0.7791 \\
\hline HDL $\mathrm{mg} / \mathrm{dl}$ & $40 \pm 9.45$ & $45 \pm 13.76$ & $<0.0001$ \\
\hline Tryglycerides $\mathrm{mg} / \mathrm{dl}$ & $118 \pm 37$ & $97 \pm 47$ & $<0.0001$ \\
\hline Total testosterone $\mathrm{ng} / \mathrm{mL}$ & $5.8 \pm 4.3$ & $1.32+1.05$ & $<0.0001$ \\
\hline Free testosterone $\mathrm{ng} / \mathrm{mL}$ & $8.39 \pm 6.69$ & $2.6+1.4$ & $<0.0001$ \\
\hline Androstenedione $\mathrm{ng} / \mathrm{mL}$ & $2.41 \pm 1.5$ & $1.04+0.68$ & $<0.0001$ \\
\hline DHEA ng/mL & $6.22 \pm 5.6$ & $1.9+0.99$ & $<0.0001$ \\
\hline
\end{tabular}

*Significant values ( $\mathrm{p}<0.05$ ), BMI, Body mass index; HOMA,Homeostatic modified assessment score; LH, Luteinizing hormone; FSH,

Follicle-stimulating hormone; HDL- High density lipoprotein; DHEA - Dehydroxy epiandrostenedione

Table 2: Genotypes and allele frequencies of FSHR polymorphism identified in the study.

\begin{tabular}{|llllll|}
\hline FSHR & GG (Ser680Ser) & GA (Ser680Asn) & AA (Asn680Asn) & A allele & G allele \\
\hline Patients & $31(15.19 \%)$ & $99(48.52 \%)$ & $74(35.29 \%)$ & $247(0.61)$ & $161(0.39)$ \\
\hline Controls & $70(34.31 \%)$ & $90(44.11 \%)$ & $44(21.56 \%)$ & $178(0.44)$ & $230(0.56)$ \\
\hline
\end{tabular}

Allele frequency odds ratio 1.98; 95\% CI 1.5-2.6; $\mathrm{p}$ value $<0.001$

Table 3: Statistical analysis of genotypes of FSHR polymorphism identified in the study.

\begin{tabular}{|llll|}
\hline Genotype & PCOS & Controls & Odds ratio 95\% CI P value \\
\hline AA versus GA+GG & $74 / 130$ & $44 / 160$ & $2.0691 .33-3.2110 .0012$ \\
\hline GA versus GG+AA & $99 / 105$ & $90 / 114$ & $1.190 .808-1.76320 .3717$ \\
\hline GG versus GA+AA & $31 / 173$ & $70 / 134$ & $0.340 .212-0.5539<0.0001$ \\
\hline
\end{tabular}

Vs - versus, PCOS - Polycystic Ovarian Syndrome, OR - Odds Ratio, CI - Confidence Interval, p - significance.

Table 4: Distribution of FSHR genotypes, Age, BMI, FG, FI, HOMA score, LH,FSH, LH/FSH in patients and controls and their comparison with Mean and Standard deviation.

\begin{tabular}{|c|c|c|c|c|c|c|c|}
\hline \multirow[t]{2}{*}{ Parameters } & \multicolumn{2}{|c|}{$\begin{array}{l}\text { A/A genotype } \\
(74 / 204)(44 / 204)\end{array}$} & \multicolumn{2}{|c|}{$\begin{array}{l}\text { A/G genotype } \\
(99 / 204)(90 / 204)\end{array}$} & \multicolumn{2}{|c|}{$\begin{array}{l}\text { G/G genotype } \\
(31 / 204)(70 / 204)\end{array}$} & \multirow[t]{2}{*}{ P value } \\
\hline & PCOS & Control & PCOS & Controls & PCOS & Controls & \\
\hline Age in years & $28.08+3.046$ & $28.18+4.9$ & $28.39+3.9$ & $27.9+5.46$ & $28.06+4.3$ & $28.6+4.8$ & 0.6578 \\
\hline BMI $\left(\mathrm{kg} / \mathrm{m}^{2}\right)$ & $27.86+4.076$ & $22.98+3.3$ & $27.43+5.4$ & $23.6+3.17$ & $24.37+4.2$ & $23.39+3.2$ & $<0.0001$ \\
\hline F glu (mg/dl) & $87.25+11.4$ & $87.8+9.01$ & $89.18+11.7$ & $89.7+12.7$ & $87.8+10.10$ & $87.2+11.9$ & 0.0001 \\
\hline $\mathrm{F}$ ins $(\mu \mathrm{IU} / \mathrm{ml})$ & $11.5+6.9$ & $6.71+4.01$ & $11.4+7.09$ & $7.18+2.99$ & $11.27+7.4$ & $6.21+3.15$ & $<0.0001$ \\
\hline HOMA score & $2.54+1.5$ & $1.5+1.1$ & $2.7+1.88$ & $1.56+0.69$ & $2.98+2.2$ & $1.2+0.62$ & $<0.0001$ \\
\hline LH (IU/l) & $12.15+6.4$ & $9.3+5.9$ & $12.01+6.3$ & $7.8+5.2$ & $11.2+4.39$ & $7.16+4.7$ & 0.0001 \\
\hline FSH (IU/l) & $5.21+1.725$ & $5.9+3.4$ & $5.5+2.2$ & $5.39+3.2$ & $5.9+2.03$ & $5.8+2.94$ & 0.0320 \\
\hline LH/FSH & $2.53+1.25$ & $1.75+1.4$ & $2.28+0.93$ & $1.5+1.2$ & $2.32+1.4$ & $1.35+1.01$ & $<0.0001$ \\
\hline
\end{tabular}

Data are shown as mean \pm SD Significant values ( $\mathrm{p}$ is $<0.05$ ), $\mathrm{P}$ values were evaluated by one-way ANOVA with Bonferroni post hoc test. Abbreviations: BMI, body mass index; W/H, waist to hip ratio; $\mathrm{F}$ glu, fasting glucose; $\mathrm{F}$ ins, fating insulin; HOMA, homeostatic model assessment score, LH- Luteinising Hormone, FSH- Follicle stimulating hormone 
The homozygous AA genotype was seen in $35.29 \%$ of patients with PCOS when compared with $21.56 \%$ of healthy controls (Table 2). Data showed that Recessive (AA vs. AG+GG), Co-Dominant (AG vs. GG+AA) genotype pattern of inheritance exhibited a significant association with PCOS (Table 3). The AA genotype was associated with PCOS (OR, 2.069; 95\% CI 1.33 to 3.21 , $P$ 0.0012). Frequency of A allele was 0.61 in PCOS and 0.44 in Controls, $(\mathrm{p}<0.0001)$; (OR 1.98, 95\% CI 1.5-2.6) (Table 2).

Body mass index, LH, and LH/FSH showed a significant elevation with Asn680Asn (AA) genotypes of PCOS $(\mathrm{p}<0.0001)$ rather than Asn680Ser (AG) and Ser680Ser (GG) genotypes when compared with age-matched healthy controls (Table 4). The GG (680Ser/Ser) variant showed elevated FSH levels, fasting insulin and HOMA score compared to other genotypes.

The genotype and allele frequencies for the 204 PCOS patients (21 A/A, 124 A/G and 59 G/G) were in HardyWeinberg equilibrium. ${ }^{15}$

\section{DISCUSSION}

The principal features of PCOS include insulin resistance, obesity, irregular menstrual cycles / anovulation and polycystic ovaries. ${ }^{6,7}$ In the present study we have noticed higher percentage of clinical hyperandrogenism features compared to meta-analysis report (Figure 1). ${ }^{6,7}$

In the present study, PCOS patients had shown significant higher levels of androgens when compared with controls (Table 1). Elevated circulating androgen levels are observed in approximately $60-80 \%$ of PCOS patients where as we observed in $44 \%$ of our PCOS cohort with elevated free testosterone (more than7.01 $\mathrm{ng} / \mathrm{mL})$.

$89 \%$ of our PCOS cohort showed irregular menstruation, higher than the meta-analysis report, and polycystic ovary (PCO) was noted in all our PCOS patients in which, $85 \%$ had shown bilateral PCO, and $15 \%$ shown unilateral PCO. ${ }^{7}$

As a complex hereditary endocrine disease, analysis of major genes associated with insulin resistance, obesity, and Hypothalamo-Pituitary-Gonadal (HPG) axis have been attempted for better understanding the pathogenesis of PCOS. The clinical manifestations of PCOS patients appear diverse in different geographic regions and different races. In this study, we assessed baseline characteristics between the PCOS patients $(n=204)$ and the controls $(n=204)$. We observed increased levels of body mass index (BMI), Luteinizing hormone (LH), LH/FSH ratio, fasting insulin and homeostatic model assessment - insulin resistance (HOMA-IR), male hormones (free and total testosterone, androstenedione and DHEA) and decreased follicle-stimulating hormone values in PCOS patients compared to controls (Table 1).
As seen with our study, the elevated serum LH levels, and LH/FSH ratio in PCOS compared to controls suggests abnormal gonadal physiology [16]. The FSHR gene loci (680) on exon 10 of FSHR have become important research topic in understanding the pathogenesis of PCOS. The SNP causes a change of serine to aspargine at position 680 , which is located in the intracellular C terminal domain. ${ }^{17}$

In the present study, we observed homozygous mutant (Asn680Asn) status in $35.29 \%$ of PCOS and $21.56 \%$ in controls. Homozygous wild status (Ser680Ser) in $15.19 \%$ in PCOS and $34.31 \%$ in controls (Table 2). Homozygous mutant (Asn/Asn) variant had shown elevated values with BMI, LH, LH/FSH levels in comparison with other genotypes (Ser/Ser and Asn/Ser). Homozygous wild type (Ser680Ser) showed low BMI, high insulin resistance and increased levels of FSH values (Table 4).

Obesity especially central adiposity manifests as the main clinical feature in PCOS. It has been reported that approximately $50 \%$ of PCOS women are overweight or obese, and most of them have central obesity. ${ }^{18}$ Based on Asia-Pacific definition of obesity, in our study, we noticed $70 \%$ of PCOS patients were obese. ${ }^{19}$ This high prevalence can be attributed to food habits and lifestyles of Indian women. The PCOS patients showed significant increased BMI compared to controls (Table 1). The Asn680Asn genotype of FSHR gene polymorphism also showed increased BMI compared to other genotypes. (Table 4).

The level of FSH is controlled by FSHR, and aberrant FSHR affects ovary and folliculogenesis. ${ }^{20}$ Similar to our study Valkenburg et al found Polymorphism rs6166 Ser680Ser is associated with high levels of FSH and followed by rs6166 Asn680Ser and rs6166 Asn680Asn genotype in PCOS, but they did not find significant association with PCOS risk as seen in our study. ${ }^{21}$

Kambalachenu HR et al in their genetic case-control study on FSHR gene polymorphism did not show any significant difference in distribution of allele or genotypes between PCOS and Controls, and found a significant association of rs6166 (Ser680Ser) genotype with PCOS in recessive model. ${ }^{22}$ But in our study we found a significant difference in distribution of allele or genotypes between PCOS and Controls, and also found significant association of rs6166 FSHR Ser680Asn polymorphism with PCOS in recessive and co-dominant model. $\mathrm{Gu}$ et al found significant association between PCOS and FSHR rs6166 (Ser680Ser) genotype in Korean women PCOS. ${ }^{20}$ But in our study we noticed significant association of PCOS risk with Asn680Asn, and Asn680Ser variants of FSHR gene polymorphism.

Unsal et al, found that the genotype frequencies of the Ser680Asn polymorphism of FSHR were not different between patients and controls in Turkish adolescent girls. ${ }^{23}$ The Ser680Asn polymorphisms of FSHR are not 
associated with PCOS in Han Chinese women of north china. $^{24}$ The SNP rs6166 in exon 10 of FSHR has been associated with PCOS in Dutch and Japanese women but not in Han Chinese population. ${ }^{21,25-27}$

Pharmacogenetic studies revealed the varied response of FSHR gene polymorphisms to exogenous FSH hormone in patients undergoing Invitro fertilization. ${ }^{17}$ In the study of position 680 in women undergoing ovarian stimulation, the results demonstrated that carriers of Ser680Ser variant had significantly higher basal FSH levels and required higher doses of exogenous FSH stimulation. Similar to our PCOS patients Yao Y et al had shown higher basal FSH levels in Ser680Ser variant. ${ }^{28}$

\section{CONCLUSION}

The FSHR Ser680Asn (rs6166) gene polymorphism is significantly associated with PCOS in our study population. The homozygous Asn680Asn variant showed significant elevation in BMI, LH, LH / FSH whereas the homozygous Ser680Ser variant showed elevated insulin resistance and basal FSH levels. So the FSHR Ser680Asn (rs6166) gene polymorphic study can be used to identify the risk associated with PCOS in our population.

\section{ACKNOWLEDGEMENTS}

We thank Department of Science and Technology, (New Delhi, India) for granting fund. Grant Number: (SR/LS91/2011/WOS-A) Dr Anuradha, Anu's fertility centre, Somajiguda, Hyderabad and Management of Kamineni Academy of Medical Sciences and Research centre, Hyderabad for helping in sample collection.

Funding: No funding sources Conflict of interest: None declared

Ethical approval: The study was approved by the Institutional Ethics Committee

\section{REFERENCES}

1. Goodarzi MO, Azziz R. Diagnosis, epidemiology and genetics of the polycystic ovary syndrome. Best Pract Res Cl En. 2006;20:193-205.

2. Simoni M, Nieschalag E, Gromoll J. Isoforms and single nucleotide polymorphisms of the FSH receptor gene: implications for human reproduction. Hum Reprod Update. 2002;8:413-21.

3. Simoni M, Gromoll J. The follicle-stimulating hormone receptor: biochemistry, molecular biology and pathophysiology. Endocr Rev. 1997;18:739-73.

4. Gromoll J, Simoni M. Genetic complexity of FSH receptor function. Trends Endocrinol Metab. 2005;16:368-73.

5. Aittomäki K, Lucena JL, Pakarinen P, Sistonen P, Tapanainen J, Gromoll J, Kaskikari R, Sankila EM, Lehväslaiho H, Engel AR, Nieschlag E, Huhtaniemi I, de la Chapelle A. Mutations in the folliclestimulating hormone receptor gene causes hereditary hypergonadotropic ovarian failure. Cell. 1995;82:959-68.

6. Azziz R, Carmina E, Dewailly D, DiamantiKandarakis E, Escobar-Morreale HF, Futterweit W, Janssen OE, Legro RS, Norman RJ, Taylor AE, Witchel SF. Position statement: Criteria for Defining PCOS as a predominantly hyperandrogenic syndrome: an androgen excess society guideline. J Clin Endocrinol Metab. 2006;91:4237-45.

7. Azziz R, Carmina E, Dewailly D, DiamantiKandarakis E, Escobar-Morreale HF, Futterweit W, Janssen OE, Legro RS, Norman RJ, Taylor AE, Witchel SF. The Androgen Excess and PCOS Society criteria for the Polycystic ovarian syndrome: the complete task force report. Fertil and Steril. 2009;91(2):456-88.

8. Ferriman D, Gallwey JD. Clinical assessment of body hair growth in women. $\mathrm{J}$ clin Endocrinol Metab. 1961;21:440-7.

9. Balen AH, Laven JS, Tan SL, Dewailly D. Ultrasound assessment of the polycystic ovary: international consensus definitions. Hum Reprod Update. 2003;9(6):305-14.

10. Govindan S, Ahamad SN, Vedicherla B, Kodati V, Rao KP, Ahuja YR, Hasan Q. Association of Progesterone receptor gene polymorphism (PROGINS) with endometriosis, uterine fibroids and breast cancer. Cancer Biomark. 2007;3:73-8.

11. Movva S, Alluri RV, Komandur S, Vattam K, Eppa K, Mukkavali KK, Mubigonda S, Saharia A, Shastry JC, Hasan Q. Relationship of angiotensin-converting gene polymorphism with nephropathy associated with type 2 diabetes mellitus in Asian Indians. J Diabetes complications. 2007;21:237-41.

12. Laven JS, Mulders AG, Suryandari DA, Gromoll J, Nieschlag E, Fauser BC, Simoni M. Folliclestimulating hormone receptor polymorphisms in women with normogonadotropic anovulatory infertility. Fertil Steril. 2003;80:986-99.

13. Kodati VL, Shetty P, Vattam K, Govindan S, Shaik NA and Hasan Q. Tumor necrosis factor alphaC850T polymorphism is significantly associated with endometriosis in Asian Indian women. Fertil Steril. 2010;94(2):453-56.

14. Liang SJ, Hsu CS, Tzeng CR, Chen $\mathrm{CH}$, and Hsu MI. Clinical and Biochemical parameters of Polycystic Ovary Syndrome between the age of 20 and 40. Hum reprod. 2011;12:3443-49.

15. Rodriguez S, Gaunt TR, Day IN. Hardy-Weinberg Equilibrium Testing of Biological Ascertainment for Mendelian Randomization studies. Am J Epidemiol. 2009;169:505-14.

16. Taylor AE. Gonadotropin dysfunction in women with polycystic ovary syndrome. Fertil Steril. 2006;86(Suppl 1):S12.

17. Mohiyiddeen L, Nardo LG. Single -nucleotide polymorphisms in the FSH receptor gene and ovarian performance: Future role in IVF. Hum Fertil. 2010;13:72-8. 
18. Gambineri A, Pelusi C, Vicennati V, Pagotto U, Pasquali R. Obesity and the polycystic ovarian syndrome. Int $\mathbf{J}$ Obes Relat Metab Disord. 2002;26:883-96.

19. Chen X, Ni R, Mo Y, Li L, Yang D. Appropriate BMI levels for PCOS patients in Southern China. Hum Reprod. 2010;25:1295-1302.

20. Gu BH, Park JM, Baek KH. Genetic variations of follicle stimulating hormone receptor are associated with polycystic ovary syndrome. Int $\mathrm{J}$ Mol Med. 2010;26:107-12.

21. Valkenburg O, Uitterlinden AG, Piersma D, Hofman A, Themmen APN, De Jong FH, Fauser BCJM, Laven JSE. Genetic polymorphisms of GnRH and gonadotropic hormone receptors affect the phenotype of polycystic ovary syndrome. Hum Reprod. 2009;24(8):2014-22.

22. Kambalachenu HR, Durairaj Paul SF, Nellepalli SR, Venkatachalam P. Study on follicle stimulating hormone receptor gene polymorphism in South Indian women with Polycystic Ovarian Syndrome. Am Med J. 2013;4(2):160-67.

23. Unsal T, Konac E, Yesilkaya E, Yilmaz A, Bideci A, Ilke Onen H, Cinaz P, Menevse A. Genetic polymorphisms of FSHR, CYP17, CYP1A1, CAP10, INSR, SERPINE1 genes in adolescent girls with polycystic ovary syndrome. J Assist Reprod Genet. 2009;26(4):205-16.

24. Wu XQ, Xu SM, Liu J F, Bi XY, Wu YX, Liu J. Association between FSHR polymorphisms and Polycystic ovary syndromea mong Chinese women in North china. J Assist Reprod Genet. 2010;31:37177.

25. Tong Y, Liao WX, Roy AC, Ng SC. Absence of mutations in the coding regions of folliclestimulating hormone receptor gene in Singapore Chinese women with premature ovarian failure and polycystic ovary syndrome. Horm Metab Res. 2001;33:221-26.

26. Sudo S, Kudo M, Wada S, Sato O, Hsueh AJ, Fujimoto S. Genetic and functional analyses of polymorphisms in human FSH receptor gene. Mol Hum Reprod 2002;8:893-99.

27. Du J, Zhang W, Guo L, Zhang Z, Shi H, Wang J, Zhang H, Gao L, Feng G, He L. Two FSHR variants, haplotypes and meta-analysis in Chinese women with premature ovarian failure and polycystic ovary syndrome. Mol Genet Metab 2010;100:292-95 .

28. Yao Y, Ma CH, Tang HL, Hu YF. Influence of follicle-stimulating hormone receptor (FSHR) Ser680Asn polymorphism on ovarian function and in-vitro fertilization outcome: a meta-analysis. Mol Genet Metab. 2011;103:388-93.

Cite this article as: Thathapudi $\mathrm{S}$, Erukkambattu J, Uma A, Kodati V, Qurratulain Annie Hasa. Association of follicle-stimulating hormone receptor gene ser680 asn (rs6166) polymorphism with polycystic ovarian syndrome. Int $\mathbf{J}$ Reprod Contracept Obstet Gynecol 2016;5:3126-32. 